[CONTRIBUTION FROM THE CHEMICAL, LABORATORIES OF THE UNIVERSITY OF DENVER]

\title{
THE SUCCESSIVE ELECTROMETRIC TITRATION OF IRON, VANADIUM AND URANIUM
}

\author{
By R. G. Gustayson and C. M. Knudson \\ Received August 5, 1922

\section{Object of Investigation}

This study of electrometric titrations was undertaken with the object of developing a single titration which would give at once the quantities of iron, vanadium and uranium present in the solution titrated. Since the charge given to a platinum electrode in contact with any solution depends directly upon the oxidizing power of the latter, if the solution contains more than one substance to be oxidized, it would seem reasonable to expect not one inflection denoting the complete oxidation of the mixture but rather as many inflections as there are oxidizable substances present, provided that the oxidation of the different components takes place successively rather than simultaneously. Therefore, it was hoped that on titrating electrometrically a mixture of salts of iron, uranium and vanadium with potassium permanganate, three distinct inflections would be observed from which the quantity of each of the metals present might be calculated. As will be shown later, the problem is more complicated than it appears at first, due to the fact that vanadium alone after reduction with a powerful reducing agent shows three distinct inflections representing the respective oxidation of each of its oxides, $\mathrm{V}_{2} \mathrm{O}_{2}, \mathrm{~V}_{2} \mathrm{O}_{3}$ and $\mathrm{V}_{2} \mathrm{O}_{4}$, to the next higher oxide. A method has been worked out, however, by which the proportion of each metal present may be calculated from the graph obtained from a single titration.

\section{Description of Apparatus}

The apparatus used in these experiments was of the general type described by Hildebrand ${ }^{1}$ with the exception that a potentiometer was used instead of the voltmeter. The platinum electrode to be dipped into the solution under investigation was, in the first experiments, constructed of a piece of platinum foil about $1 \mathrm{~cm}$. square welded to a platinum wire. In the latter part of the work, instead of the platinum foil, simply a piece of platinum wire was used, as the smaller surface seemed to give steadier readings. This fact has been previously recorded by Hostetter and Roberts. ${ }^{2}$

As a large number of titrations had to be carried out in an atmosphere of carbon dioxide, as will be shown later, some additional apparatus was found necessary. A 3-necked Wolff bottle was fitted up as the titrating vessel. One of the side necks was equipped with a 2-holed rubber stopper carrying the salt bridge of the calomel electrode and the inlet for the carbon dioxide. The other was fitted with a 3-holed rubber stopper, through 1 hole of which was inserted the platinum electrode, through a second hole, the tip of the buret, while the third was left open to permit the escape of the carbon dioxide. In the middle neck was placed the automatic stirring device, which was operated by a small electric motor.

1 Hildebrand, This Journal, 35, 843 (1913).

${ }^{2}$ Hostetter and Roberts, ThIs Journal, 41, 1337 (1919). 


\section{Experimental}

A survey of the literature shows that reducing agents which reduce uranium to a valence of 4 , will also reduce vanadium to a valence of 2 . Consequently, it is not feasible to use a reducing agent which will only reduce vanadium to the tetravalent state, and make it possible to obtain only the 3 end-points indicating iron, vanadium and uranium, respectively. As zine with sulfuric acid was found to reduce all 3 elements, it was chosen as the reducing agent for the succeeding experiments.

A study was made of the curvess obtained when the 3 substances were reduced and titrated separately. The curves representing iron and uranium, respectively, titrated with potassium permanganate after reduction with zine were found to be simple curves containing only the one inflection representing the end-point of the titration. Curve A, Fig, 1, on the other hand, representing varladium treated similarly, was found to contain three definite inflections indicating, respectively, the endpoints in the oxidation of each of the different oxides of ranadium, $\mathrm{V}_{2} \mathrm{O}_{2}, \mathrm{~V}_{2} \mathrm{O}_{3}$ and $\mathrm{V}_{2} \mathrm{O}_{4}$, to the next higher oxide. As was found by Hil-

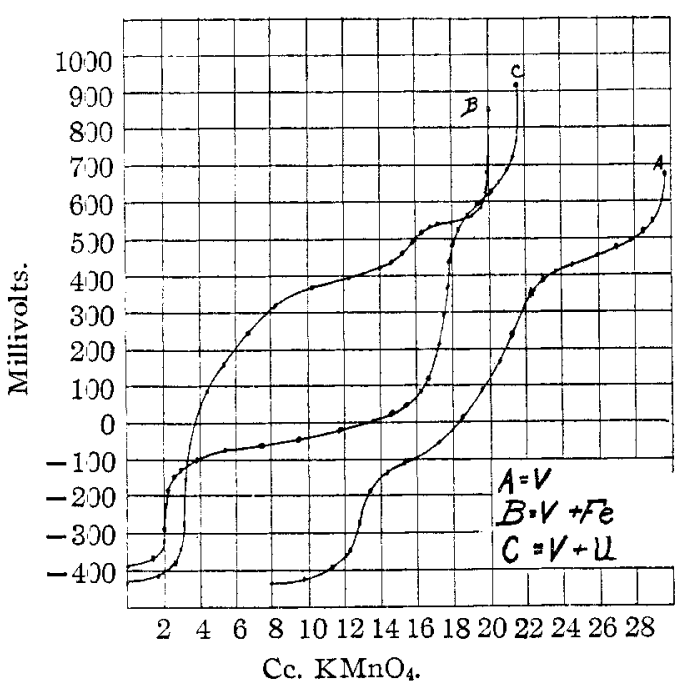

Fig. 1. debrand in the titration of iron with dichromate, so in this titration of vanadium, a high acidity, about $50 \mathrm{cc}$. of conc. sulfuric to $250 \mathrm{cc}$. of the solution, was found to favor sharp inflections at the different end-points. This titration of vanadium and all other titrations described which include vanadium were performed in an atmosphere of carbon dioxide in the apparatus previously described, as it was found impossible to obtain checking results when exposed to the air, due to the action of oxygen on the lower oxides of vanadium.

Since the completion of this work, an article by Ewing and Eldridge has appeared, in which the electronetric titration of uranium is discussed. ${ }^{3}$ They find that uranium when titrated in as great an acidity as $20 \mathrm{cc}$. of strong sulfuric acid per $100 \mathrm{cc}$. of solution gives a curve which rises rapidly at first and then becomes practically horizontal, making the determination of an end-point by the electrometric method impossible.

${ }^{3}$ Ewing and Eldridge, Thrs Journat, 44, 1484 (1922). 
Our results, on the contrary, show a very definite vertical portion of the curve representing the end-point, even when the concentration of acid was as high as $60 \mathrm{cc}$. of conc. sulfuric acid to $250 \mathrm{cc}$. of solution, a slightly greater concentration than that used in the determination referred to.

\section{Uranium and Iron}

Attention was next turned to all possible combinations of 2 elements. The first to be worked out was one involving a mixture of uranyl acetate and ferric sulfate. It was found that the successful titration of these elements depends upon maintaining low acid concentrations. Acid concentrations as high as $15 \mathrm{cc}$. of conc. sulfuric acid to $250 \mathrm{cc}$. gave curves which overlap, rendering separate titrations impossible. In other words, in high acid concentrations the elements seem to be oxidized simulta-

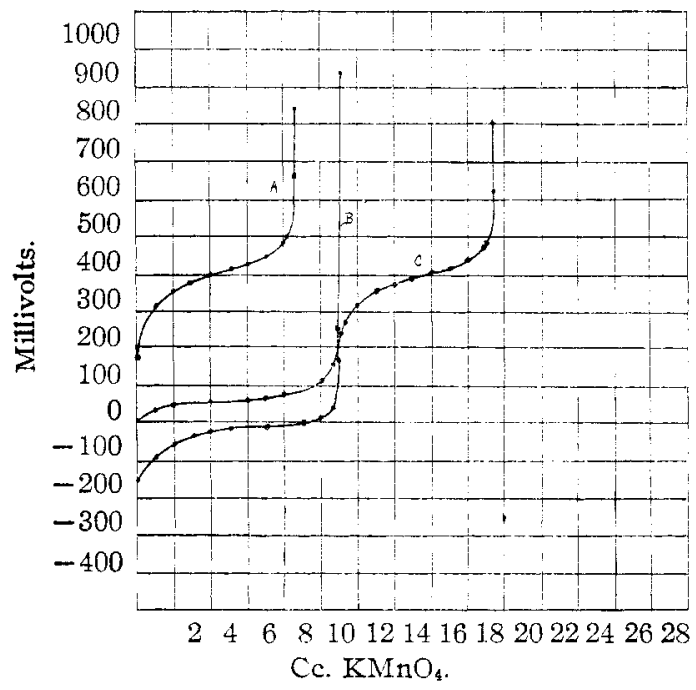

Fig. 2.-Titrations of iron and utanium.

$\mathrm{A}=$ iron; $\mathrm{B}=$ uranium; and $\mathrm{C}=$ iron + uranium, each with the addition of $5 \mathrm{cc}$. of sulfuric acid. neously rather than successively. In Fig. 2, Curve A represents the titration of $250 \mathrm{cc}$. of ferric sulfate solution containing $41.1 \mathrm{mg}$. of iron, acidified with $5 \mathrm{cc}$. of conc. sulfuric acid and reduced with $5 \mathrm{~g}$. of zinc for 20 minutes. Curve B, Fig. 2 , represents the titration of $250 \mathrm{cc}$. of uranyl acetate, containing $121 \mathrm{mg}$. of uranium, after being acidified with $5 \mathrm{cc}$. of conc. sulfuric acid and reduced with zine for 20 minutes. Curve $C$, Fig. 2, is the result of titrating a mixture of the iron and uranium salts, containing the same quantities of iron and uranium that Curves $A$ and $B$ represent. It will be noticed that the end-point for uranium in the mixture checks exactly with that obtained when it is titrated alone while the portion representing the iron in the mixture is $8.3 \mathrm{cc}$, which checks the result obtained when titrating the iron alone. A study of the curves showed that decreasing the acidity of the solution throws the range of potential of the uranium during oxidation much lower in the voltage scale, while the range for iron is not greatly altered. This makes possible the sharp inflections obtained in the last curve.

\section{Vanadium and Iron}

Curve B, Fig. 1, indicates the results obtained by titrating $250 \mathrm{cc}$. of 
a mixture of iron and vanadyl sulfates after reduction with zinc and 10 cc. of conc. sulfuric acid. The volume of permanganate represented between the first and second inflections includes both the quantity necessary to oxidize the iron and that required to oxidize the vanadium trioxide to tetroxide. If the titration of the vanadium tetroxide as represented by the difference between the second and third inflections is subtracted from that between the first and second, we have the volume used by the iron. Applying this to the curve we obtain $8.2 \mathrm{cc}$. for the iron which agrees with the former result for iron.

\section{Vanadium and Uranium}

Curve C, Fig. 1, represents the titration of $250 \mathrm{cc}$. of a mixture of vanadyl sulfate and uranium acetate, containing $18.7 \mathrm{mg}$. of vanadium and 121 $\mathrm{mg}$. of uranium, reduced with $5 \mathrm{~g}$. of zinc for 30 minutes in the presence of $10 \mathrm{cc}$. of conc. sulfuric acid. In this instance as in that of the iron and vanadium mixture, the volume between the first two inflections includes all of the uranium and one of the vanadium oxides. Therefore, subtracting the volumes between the last two inflections we have $11.0 \mathrm{cc}$. as the titration value of the uranium.

\section{Vanadium, Uranium and Iron}

The final step was to titrate a mixture of all three of these metals. For this purpose, samples were prepared containing $10 \mathrm{cc}$. of ferrous sulfate containing $41.1 \mathrm{mg}$. of iron, $20 \mathrm{cc}$. of vanadyl sulfate solution containing $18.7 \mathrm{mg}$. of vanadium and $25 \mathrm{cc}$. of uranyl acetate solution containing 121 $\mathrm{mg}$. of uranium. This mixture was diluted to $250 \mathrm{cc}$. and $5 \mathrm{~g}$. of zinc and various quantities of acid were added. After each sample had boiled for 30 minutes it was filtered through cotton and titrated while hot with permanganate solution in an atmosphere of carbon dioxide. A study of the curves obtained indicated that a low acidity is necessary for the first part of the titration while a higher acidity is required in the latter part. Curve A, Fig. 3, is an attempt to use $7 \mathrm{cc}$. of conc. sulfuric acid and shows that the end-points are indefinite. An attempt was made using $4 \mathrm{cc}$. of sulfuric acid to begin with, then after the second inflection had been observed, adding another $4 \mathrm{cc}$. and continuing the titration. As is evident from Curve B, Fig. 3 the attempt was highly successful, as quite definite end-points are obtained at all the possible points. The volume between the third inflection and the final inflection represents one step in the oxidation of the vanadium, that between the second and third inflections represents the iron, while the volume between the first and second inflections includes the permanganate necessary to oxidize all of the uranium present, and also one oxide of vanadium to the next higher oxide. As the permanganate consumed in the oxidizing of vanadium trioxide to the tetroxide must be the same as that required to oxidize 
the latter to the pentoxide, we can find the volume representing the uranium present by subtracting the volume representing the latter oxidation from that between the first and second inflections. Thus it is possible from the data of a single titration to calculate the quantities of iron, vanadium and uranium present in a mixture.

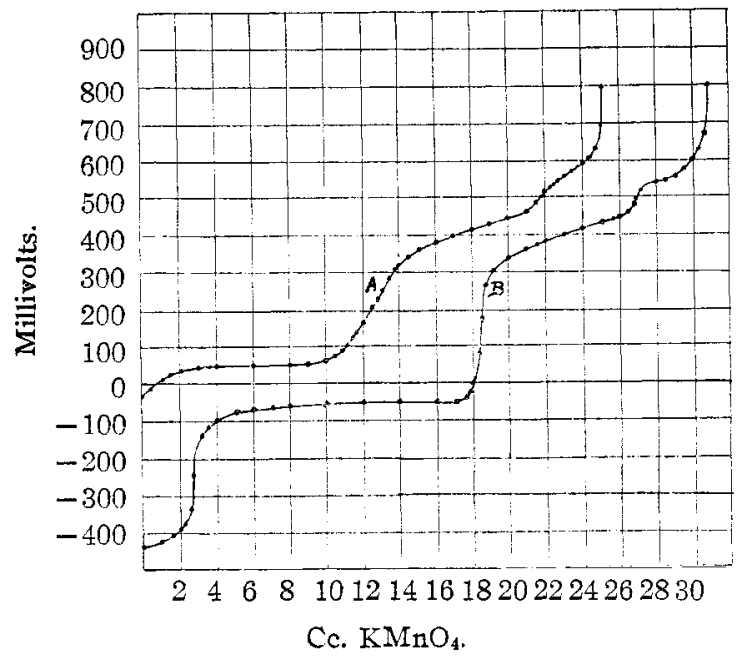

Fig. 3.-Titrations of iron, vanadium and uranium.

$A=7 \mathrm{cc}$. of sulfuric acid; $B=2$ lots of $4 \mathrm{cc}$. each of sulfuric acid added during titration.

The following table is a comparison of the quantities of iron, vanadium and uranium as found by the new method with the quantities present as de-

TABLE I

\begin{tabular}{|c|c|c|c|c|c|c|c|c|}
\hline & Elements & $\mathrm{H}_{2} \mathrm{SO}_{4}$ & & & & & Vana & lium \\
\hline aple & present pe & er $250 \mathrm{cc}$ & Present & & Present & Found & Present & Fou \\
\hline & & C.c. & G. & G. & G. & G. & & \\
\hline 83 & V & 15 & & & & & 0.0187 & 01 \\
\hline 89 & V & 25 & & & $\ldots$ & 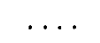 & 0.0187 & 0.0 \\
\hline 90 & $\mathrm{~V}$ & 50 & & & & & 0.0187 & 0.0 \\
\hline 107 & $\mathrm{Fe}+\mathrm{U}$ & 5 & 0.0411 & 0.0408 & 0.1210 & 0.1173 & & \\
\hline & & 5 & & $\cdots$ & 0.1210 & 0.1192 & 0.0187 & .0 \\
\hline 15 & $\mathrm{U}$ & 10 & $\ldots$ & $\cdots$ & 0.1210 & 0.1182 & 0.0 & 0. \\
\hline & & & & & 0.1210 & 0.1202 & 0.0280 & 0.0 \\
\hline 27 & $\mathrm{U}$ & $4+5$ & & & 0.1210 & 0.1190 & 0.0280 & 0.0 \\
\hline & & 10 & 11 & 0.0408 & & $\ldots$ & & \\
\hline 125 & $\mathrm{v}$ & 4. & 0411 & 0.0424 & & & 0.0280 & 0.0 \\
\hline & & & 0.0411 & 0.0 & & & 0.0280 & \\
\hline 19 & $+\mathrm{U}$ & & 0.0411 & 0.0408 & 0.1210 & 0.1192 & 0.0187 & \\
\hline 121 & & & & & 0.1 & 0. & 0.0187 & \\
\hline 122 & & & 1 & 24 & .1210 & 1215 & .0187 & \\
\hline
\end{tabular}

termined by standard methods of analysis. The vanadium was determined by three different methods. Permanganate was used as the standard 
solution, but the reducing agents varied. The value of $0.0188 \mathrm{~g}$. of vanadium in $20 \mathrm{cc}$. was obtained by both the ferrous sulfate and hydrogen peroxide methods, while 0.0185 was found when sulfurous acid was the reducing agent. Therefore $0.0187 \mathrm{~g}$. in $20 \mathrm{cc}$. was taken as the amount present. The iron and uranium were determined by the usual volumetric methods, reducing them with zinc and titrating with potassium permanganate without obtaining the end-point electrometrically The uranium solutions were poured through air to oxidize any lower oxides to the tetravalent condition.' A Study of the problem is being continued.

\section{Surnmary}

Analyses of salts of iron, vanadium and uranium have been studied by the electrometric method, individually and in all possible combinations, and a number of curves plotted indicating the results.

1. Iron, vanadium and uranium may each be titrated electrometrically after reduction with zinc and sulfuric acid, but in the case of vanadium the titration must be carried out in an indifferent atmosphere such as carbon dioxide. A high concentration of acid favors sharp inflections at all three end-points in the vanadium titration.

2. Mixtures of salts of iron and uranium may be titrated with permanganate after reduction with zinc and sulfuric acid by the electrometric method, provided that the acidity is kept low, the optimum concentration being about $5 \mathrm{cc}$. of conc. sulfuric acid to $250 \mathrm{cc}$. of solution.

3 . Iron and vanadium in mixtures may be determined by a similar method using $10 \mathrm{cc}$. of acid to $250 \mathrm{cc}$. of solution, but in this case the titration must be made in an atmosphere of carbon dioxide to obtain reliable results. The volume representing the vanadium is obtained directly from the final step in the curve, while that representing uranium can be obtained by subtracting this value from the first step of the same curve.

4. The determination of vanadium and uranium in mixtures when 5 to $10 \mathrm{cc}$. of sulfuric acid is present may be made by titrating the mixture in a non-oxidizing atmosphere. The vanadium is obtained directly as before, and the uranium by difference.

5. When all 3 elements, iron, vanadium and uranium, are present, the determination may be made similarly. It is best to use $4 \mathrm{cc}$. of sulfuric acid to $250 \mathrm{cc}$. of solution for the first part of the titration, and then, after the second inflection is obtained, a like quantity of acid is added and the titration continued. The vanadium and iron are represented by the last and the next to the last steps, respectively, while the uranium is again found by subtracting the value found for vanadium from the value indicated in the portion of the curve between the first and second inflections.

I ENVER, COLORADO 